\title{
Challenges of Iranian Maternal Health Program from Midwives' Perspectives: A Qualitative Study
}

\author{
Rozita Firouznia ${ }^{1,{ }^{*}, \text { Hossein Dargahi }}{ }^{2}$, Tohid Jafari Koshki ${ }^{3}$ and Zeinab Khaledian ${ }^{4}$ \\ ${ }^{1}$ Department of Health Services Management, Semnan Branch, Islamic Azad University, Semnan, Iran \\ ${ }^{2}$ Department of Management and Health Economics, Health Information Management Research Center, School of Public Health, Tehran University of Medical Sciences, \\ Tehran, Iran \\ ${ }^{3}$ Department of Statistics and Epidemiology, Road Traffic Injury Research Center, Faculty of Health, Tabriz University of Medical Sciences, Tabriz, Iran \\ ${ }^{4}$ Department of Midwifery, Semnan Branch, Islamic Azad University, Semnan, Iran \\ "Corresponding author: Department of Health Services Management, Semnan Branch, Islamic Azad University, Semnan, Iran. Email: firouzniahsm@gmail.com
}

Received 2019 April 16; Revised 2019 May 29; Accepted 2019 June 16.

\begin{abstract}
Background: Maternal health program is one of the most important programs in Iran primary health care (PHC). Considering the necessity of its continuous quality improvement, the present study was designed to identify the challenges of Iran maternal health program from the midwives' perspectives.

Methods: This is a qualitative study with 27 midwives working in East Azerbaijan province PHC system. The sampling method was purposeful and the inclusion criterion for participants included at least 5 years of experience in the maternal health program. The researchers conducted eight individual and group unstructured interviews and the content analysis method was used for data analysis.

Results: This study identified 9 themes, 16 subthemes, and 39 items related to the challenges of the maternal health program from the midwives' perspectives. The main identified themes were human resources, information management, service continuity, cultural barriers, legal and administrative barriers, care facilities, medical equipment, monitoring and evaluation, and geographic access.

Conclusions: The study results indicated that there are significant challenges to the maternal health program, which implies the urgent attention of the managers and policymakers to designing and implementing effective interventions.
\end{abstract}

Keywords: Challenge, Maternal Health Program, Midwife, Iran

\section{Background}

Maternal health is one of the main domains in primary health care (PHC) systems (1), but its status is still not satisfactory especially in developing countries so that about 287,000 women die annually due to birth defects, of which 99\% occur in developing countries (2-4). Accordingly, since the introduction of the millennium development goals (MDGs) in the1990s, maternal health has been highlighted as a global priority, but the death rate of mothers is not at an acceptable level in many developing countries (5). In 2015, there were 303,000 maternal deaths globally (6) and South-Saharan Africa and Southeast Asia alone accounted for $59 \%$ of all deaths $(7,8)$.

The notable point is that most deaths and complications are avoidable by increasing access to high-quality maternal care (9-11). Various studies indicated that providing inadequate and low-quality care can result in increasing the risk of stillbirth, low birth weight, premature babies, pregnancy problems, and maternal mortality (12-17). According to the reports of the World Health Organization in 2010 and 2014, maternal mortality reduction in Iran was estimated at $81 \%$ and $72 \%$, respectively, which showed significant adaptation to the millennium development goals (2). Annually, about one million women give birth in Iran; the maternal mortality is 18.1 per 100,000 births, the death rate of infants is 12 per 1,000 live births, and the rate of cesarean section is $47.5 \%$, which are still higher than the corresponding rates in developed countries $(18,19)$.

Studies have shown that a high percentage of pregnant women receive maternal care less than the normal level. For example, $23.5 \%$ of pregnant women in Iran have less than two referrals for receiving maternal care during pregnancy $(20,21)$. Of the 295 registered deaths of mothers in Iran in $2005,87.6 \%$ were related to hospitalized mothers and $60 \%$ were due to medical errors (22). Studies indicate that some areas of maternal care program are not qualified, including support groups, timely attention, rapid pre- 
vention and detection, service continuity, respect, safety, access, and basic facilities (23).

As many maternal deaths can be prevented by providing high-quality care (24), quality improvement has been considered as one of the five global strategies for improving maternal health programs (25-27). One of the prerequisites for quality improvement in healthcare, especially in maternal health, is the assessment of different dimensions of care, especially with qualitative approaches in the perspectives of providers and recipients of the services (2830).

\section{Objectives}

Accordingly, the present study was designed to investigate the challenges of Iranian maternal health program from the perspective of midwifery personnel working in the PHC field.

\section{Methods}

This qualitative study was carried out with the participation of 27 midwives working in maternal health program of East Azerbaijan province, Iran. The only inclusion criterion for participants was having at least 5 years of experience in the maternal health program. Purposeful sampling was used to select the participants because this sampling method is used for selecting those who are able to provide the best and the richest views and experiences to the study. This sampling method allows the research team to identify the conceptual patterns in the minds of different people in relation to the nature of events (31).

In this study, the researchers followed an unstructured method to conduct two group interviews and six individual interviews with participants to obtain their views on the challenges of the maternal health program in the PHC of Iran. The duration of individual interviews varied from 60 minutes to 90 minutes and the duration of group interviews varied from 120 minutes to 150 minutes. The interviews were recorded using audio recorders and then transcribed verbatim. All the interviews continued until data saturation reached, that is the statements were repeated and no new idea emerged (32).

To analyze the obtained data, a content analysis method was used in which the underlying concepts in the data were extracted, interpreted, and reported using a systematic approach (33). At the data implementation stage, all materials were recorded on paper and checked to ensure the correctness of the process. In the next step, the coding process started in which, the experiences expressed by the participants were presented in the form of codes or items (text phrases representing the content of the statements). Then, based on the apparent and hidden themes in the codes, the same codes were placed next to each other to form the sub-themes of the study. Finally, the main themes of the study were created and labeled with the integration of sub-themes. At the stage of interpreting the findings, which included searching for patterns, relationships, concepts, and interpretations in the data, the researchers examined the final themes developed to interpret their ideas and contents (34).

In order to improve and confirm the rigor of the study, two researchers separately participated in the data analysis stage. Consequently, the results of the analyses were compared by one external researcher and agreements were obtained with the final findings. In addition, the interview results were given to all interviewees to be approved. In addition, after identifying all the themes, adjectives, and related items, two experts in qualitative study and maternal health program were asked to confirm their correctness.

In order to follow the ethical principles, the research project was approved by the Ethics Committee of Islamic Azad University and informed consent was obtained from the participants. Furthermore, oral permission was obtained to record the interviews using a tape recorder and the confidentiality of all information and maintenance of the identity of interviewees were ensured.

\section{Results}

This study identified 9 themes, 16 subthemes, and 39 items related to the challenges of the maternal health program (Table 1).

\subsection{Workforce}

\subsubsection{Quality of Workforce}

The main challenges described by the participants included the limited ability of non-midwifery health personnel in care delivery to pregnant mothers, aged midwives, and low motivation due to inadequate and unsatisfying payments. According to the midwives, "Both groups of midwives and family health experts work with the title of healthcare providers and have similar tasks, but family health experts have absolutely no knowledge and experience in this area. Many midwives are aged and have really low physical ability" (interview No.1).

\subsubsection{Quantity of Workforce}

Contributors believed, "While the number of maternal care related activities is high, there are not enough midwives and family health professionals to provide quality work or meet some expectations of higher managerial levels" (interview No. 5). 


\begin{tabular}{|c|c|}
\hline Main Themes/Sub-Themes & Relevant Codes \\
\hline \multicolumn{2}{|l|}{ Workforce } \\
\hline \multirow{3}{*}{ Workforce quality } & - Low-income of non-midwifery healthcare personnel in maternal care \\
\hline & - Physical weakness of many midwives due to the relatively high age \\
\hline & - Low motivation in many midwives because of low payments \\
\hline \multirow{2}{*}{ Workforce quantity } & - Lack of workers in this area, especially midwives \\
\hline & - Lack of female college experts at some government centers \\
\hline \multirow{3}{*}{ Scope of tasks } & - A large number of duties and activities in the area of maternal health \\
\hline & - High pressure on midwives, especially during peak hours \\
\hline & - The excessive workload of other health personnel on midwives \\
\hline \multicolumn{2}{|l|}{ Information management } \\
\hline \multirow{4}{*}{ The initial design of the system } & -A large number of questions in the care system mostly unnecessary \\
\hline & - Not having a user-friendly system \\
\hline & - Non-compliance of the system with protocols in some professional activities \\
\hline & - The dual role defined for midwives in the system \\
\hline \multirow{2}{*}{ Data entry to the system } & - Unrealistic register services in the system \\
\hline & - Low speed of care system \\
\hline \multirow{3}{*}{ Production and sharing of information } & - Creating false statistics due to unregistered care records \\
\hline & - Unmatched production information in the system \\
\hline & - Lack of health personnel access to production information \\
\hline \multirow{2}{*}{ Paper records } & - Lack of paper records \\
\hline & - Lack of alternative paper forms for use during system disturbances \\
\hline \multicolumn{2}{|l|}{ Continuity of service } \\
\hline \multirow{2}{*}{ Continuity and integrity of the service } & - The absence of a caring midwife at the time of delivery \\
\hline & - Lack of coordination with private and public centers \\
\hline \multirow{4}{*}{ Referral system } & - The problem in the early detection of pregnant women in cities \\
\hline & - Poor interaction of hospitals with centers in referrals \\
\hline & - Unnecessary referral of patients by doctors \\
\hline & - Little tendency of mothers to receive services from government centers \\
\hline \multirow{3}{*}{ Cultural barriers Legal and administrative barriers } & - Unrealistic expectations of mothers from midwives, especially in rural areas \\
\hline & - Use of the healthcare provider title for the midwife \\
\hline & - Quantitativeness in the field of maternal care \\
\hline \multirow{4}{*}{ Care delivery physical spaces } & - Lack of an examination room for midwifery activities \\
\hline & - Too many stairs and no lift \\
\hline & - The poor physical conditions of government centers \\
\hline & $\begin{array}{l}\text { - The inadequacy of equipment at private maternal care centers, such as scales } \\
\text { and barometers }\end{array}$ \\
\hline \multirow{2}{*}{ Medical devices } & - Defective equipment such as barometers \\
\hline & -Limited laboratory facilities for pregnancy care \\
\hline \multicolumn{2}{|l|}{ Monitoring and evaluation } \\
\hline \multirow{2}{*}{ Evaluation criteria } & $\begin{array}{l}\text { - Focusing on quantitative evaluation and neglect of quality assessment } \\
\text { indicators }\end{array}$ \\
\hline & - Highly defined indicators and norms for evaluation \\
\hline \multirow{2}{*}{ Evaluation process } & - Poor verification of provided health statistics \\
\hline & - Poor supervision of care, especially at private centers \\
\hline Geographical access & - The inappropriate geographical location of the health center \\
\hline
\end{tabular}

\subsubsection{Scope of Tasks}

The participants declared, "High workload, especially during peak hours, and over-crowdedness of the facility during peak hours cause disturbances, fatigue, and poor quality care" (interview No. 1). 


\subsection{Information Management}

\subsubsection{The Initial Design of the System}

As the main challenges identified in this study we can mention problems related to the national clinical information system entitled "SIB." The participants complained, "The lack of attention to the huge workload of the personnel at the time of designing the system is obvious; there are loads of unnecessary paperwork and bureaucracy in the system" (interview No. 2).

\subsubsection{Data Entry to the System}

Contributors state, "Midwives and other healthcare providers in maternal wards register some false and unreal services, which would surely be misleading and inappropriate in statistics" (interview No. 2).

\subsubsection{Production and Sharing of Information}

The contributors stated, "It is not clear what information is extracted from the system and where this information is to be used; it seems that there is an excess of information; in some cases, there is an information gap in such a way that even those who care to complete the system information do not have access to the data and information" (interview No. 2).

\subsubsection{Paper Records}

Another challenge was the lack of paper records and forms for the care process. Contributors believed, "The paper records have been eliminated and it takes time for paper records and SIB electronic system records to work in parallel until the transition and progress are gradually achieved" (interview No. 6).

\subsection{Continuity of the Service}

\subsubsection{Continuity and Integrity of the Service}

Participants expressed, "Pregnant women have a close and emotional relationship with their own midwives. Besides, these midwives are fully aware of the patient's mental and physical conditions and their presence during the delivery phase, so they can reduce stress in mothers and help them have a relaxed delivery" (interview No. 2).

\subsubsection{Referral System}

Participants believed, "Hospitals do not have a positive relationship with health centers and there are no defined processes for referring the patients from health centers to hospitals, and hospitals do not consider the patients' special conditions" (interview No. 7).

\subsection{Cultural Barriers}

The first shortcoming is the low tendency of mothers to receive services from governmental centers. In this regard, one of the participants claimed, "Physicians and midwives working in the private sector misjudge the quality of cares provided by public centers in order to falsely boost their own reputation and popularity although mortality and pregnancy-related problems in our system are much lower than theirs" (interview No. 2).

\subsection{Legal and Administrative Barriers}

One of the challenges in this regard is the use of the title "healthcare provider" for midwives. Participants stated, "Mothers have not heard about this title and cannot trust it; it is necessary to change this term because people are traditionally accustomed to the well-known title of the midwife" (interview No. 3). In addition, "The quantityoriented view of healthcare managers and its reflection in defined regulations, circulars, and norms are the other challenge" (interview 4).

\subsection{Care Delivery Physical Spaces}

Contributors stated, "The examination spaces are severely limited and they are not partitioned, so the privacy of mothers is not met; many buildings have a lot of stairs without a lift and mothers have many problems to come to the health centers, especially in the last months of pregnancy" (interview No. 4).

\subsection{Medical Devices}

Contributors stated, "In many cases, defective equipment such as barometers is used, resulting in poor service quality; they are not usually calibrated for accuracy and quality" (interview No. 7).

\subsection{Monitoring and Evaluation}

\subsubsection{Evaluation Criteria}

The mentioned challenges are mainly associated with quantitative indicators and it seems that qualitative indicators have been neglected. In this regard, contributors believed, "The care indicators defined for evaluating midwives are mainly quantitative, excessive, and very unrealistic and the quality of services has not been highlighted" (interview No. 4).

\subsubsection{Evaluation Process}

The first challenge in this area is the small number of evaluations for the correctness of statistics reported by the midwives. Contributors believed, "In many parts of the country, there is no accurate and targeted verification of statistics provided by the healthcare providers" (interview No. 5). 


\subsubsection{Geographical Access}

Participants claimed, "In some cases, the location of health centers is not suitable and people are reluctant to refer to care providers because of their remoteness or marginalization, especially in newly built residential areas that are not still populated" (interview No. 7).

\section{Discussion}

In order to categorize the identified challenges in this study into four aspects of context, input, process, and product, the context, inputs, process and product (CIPP) evaluation model was used as the framework $(35,36)$. In the context dimension, cultural barriers along with legal and administrative barriers were identified as major challenges in the maternal health program. Regarding the mentioned cultural barriers, it was noticed that the general view of society, especially pregnant women living in cities, was not positive toward the prenatal care provided in the public PHC system, and they preferred to receive the required services from private centers. In addition, some of the legal barriers such as "not using the title of the midwife" and "the dominance of quantity-oriented view in the system of maternal health program" are other notable challenges. To overcome such challenges, the following measurements might be taken: public reporting of updated statistics regarding the performance of maternal health centers, providing suitable education to pregnant women and their families, designing and implementing a proper and efficient referral system, preventing the delivery of maternal cares by non-midwifery personnel, and changing managerial tendencies toward qualitative performance and statistics.

In this study, the most challenging problems were related to the inputs for providing effective cares during pregnancy, such as workforce, information management, care facilities, and medical equipment. In addition, participants did not consider the quantity and quality of midwives to be sufficient in terms of number and scope of their duties and activities. They also identified "unnecessary items defined in the SIB system" and "the lack of access to some information defined in the system" as major challenges related to the information system. In addition, the quality and quantity of the utilized medical equipment and devices are not at a desirable level. Accordingly, determining the midwife-to-birth ratio in a scientific way, matching the volume of cares and duties, highlighting the role of university education, and training midwifery skills can help overcome the existing challenges. In addition, the implementation of scientific and targeted management in the production process and flow of health information in the system is a managerial decision-making tool that can be helpful for information. Therefore, it is necessary to conduct all the stages of designing information systems, collecting data, logging into the system, analyzing and producing information, and storing and distributing the information in a fully targeted and need-based manner. In addition, in the dimension of inputs, in addition to the necessity of extending and modernizing physical spaces, it is possible to provide and calibrate the appropriate medical equipment used in the field of maternal health as a priority intervention.

In the dimension of the processes associated with the maternal health program, there were also challenges to the participants in three areas of service continuity, geographical accessibility, and monitoring/evaluation. The major problems in these three areas included the lack of integration in the maternal health program between public and private providers, existence of referral disruptions in the referral system, impairment in the continuity of care provided by midwives, inappropriate geographical location of some health centers, and problems associated with monitoring tools and processes related to maternal health program. To address these challenges, the following measures might be taken: designing and implementing effective and continuous interventions such as redefining prenatal care with the aim of eliminating gaps and overlapping cares, designing and implementing an efficient and proper referral system, choosing appropriate geographical locations for care centers, and designing and using appropriate scientific tools for evaluating the maternal health program through an effective and efficient evaluation process.

In their study, Ahmadi and Yazdi emphasized the role of midwifery training as an important challenge in the maternal health program. They identified the shortcomings of midwifery training in three main aspects, including the weakness of educational program (inadequate educational environment, failure of practical skills, lack of appropriate training sources, and inappropriate ways of teaching), insufficient ability of educators (conservatism of educators, insufficient knowledge and experience of instructors, and insufficient support for educators), and failures in the field of study (graduate curriculum restrictions, limitations and lack of diversity in the post-graduation period, and dissatisfaction of studying). These results are consistent with the findings of our study (37).

In another study by Moghasemi et al. it was concluded, "The Iranian midwifery care system has a poor body of knowledge and research, as well as intervention background. Further, there is no proper and comprehensive understanding of the needs of women, men, and families regarding midwifery care.” The results of this study did not pay attention to this topic (38).

The study by Makvandi et al. showed that "low moti- 
vation of midwives in performing physiologic childbirth, barriers related to workforce, medical interventions in physiologic childbirth, challenges from the environment and facilities, and educational barriers" were the main challenges to implementing physiologic childbirth (39).

The study by Joulaei et al. revealed, "Although a significant reduction has occurred in the maternal mortality rate, which dropped from 83 to 23 per 100,000 (births) between 1990 and 2013, there is (still) no equal distribution in maternal mortality across the country as manifested by the unfavorable conditions of border provinces" (40). In a similar study, Mohammadi et al. showed, "Between 1990 and 2015 , the median annual reduction and total overall reduction rates were $4.9 \%$ and $70 \%$, respectively. Iran and most of its provinces achieved the MDGs by 2015. However, at the subnational level in some provinces, there is substantial inequity. Based on the MDGs, five provinces could not decrease child mortality by two-thirds by 2015" (41).

The notable point in the results of our study is that none of the participants paid attention to the challenges related to product indicators in prenatal care, which can be attributed to their excessive involvement in the processes and daily activities or the weakness of their systemic and outcome-oriented view (often associated with inputs and processes).

The main strengths of this study include the holding of acceptable numbers of individual and group interviews, precise and targeted selection of individuals with knowledge and experience to participate in the study, and the variety and novelty of the extraction themes from the interviews. The main limitation of this study was the lack of similar studies to be compared with our results.

\subsection{Conclusions}

The value and significance of maternal health are evident in every society due to its direct impact on having healthy and productive generations. Therefore, the promotion of maternal care is an irrefutable necessity and an important task in all health systems. The present study attempted first to present some major challenges to the maternal health program of Iran, which led to identifying notable shortcomings in human resources, information management, service continuity, cultural barriers, legal and administrative barriers, care facilities, medical equipment, monitoring and evaluation, and geographic access. This study also offered practical suggestions to eliminate these challenges based on the views of the process owners and the stakeholders of the program, such as enhancing the health workers competencies, developing purposeful clinical information systems, implementing effective referral systems, educating the families regarding appropriateness of delivered services by the public PHC system, emphasis on the quality of care rather than quantity, providing proper physical space and equipment for care delivering environment, designing suitable tools and processes for evaluation, and establishing healthcare centers appropriately concerning caregivers locations. Undoubtedly, the results of this study concerning identified challenges and proposed strategies can be helpful for the managers and policymakers of Iran maternal health program for future planning.

\section{Acknowledgments}

The researchers would like to appreciate the sincere collaboration of all the participants who provided valuable and accurate information in interviews.

\section{Footnotes}

Authors' Contribution: All stages of the study were jointly done by the authors.

Conflict of Interests: The researchers declare that there is no conflict of interest.

Ethical Considerations: The study was approved by the Ethics Committee from the Islamic Azad University (IR.IAU.SEMNAN.REC.1397.001).

Funding/Support: The study was conducted without any financial support.

\section{References}

1. Goberna-Tricas J, Banus-Gimenez MR, Palacio-Tauste A, LinaresSancho S. Satisfaction with pregnancy and birth services: the quality of maternity care services as experienced by women. Midwifery. 2011;27(6):e231-7. doi: 10.1016/j.midw.2010.10.004. [PubMed: 21145632].

2. World Health Organization. Trends in maternal mortality: 1990 to 2013. Estimates by WHO, UNICEF, UNFPA, The World Bank and the United Nations Population Division. Geneva: WHO Press; 2014.

3. Lawn JE, Cousens S, Zupan J, Lancet Neonatal Survival Steering T. 4 million neonatal deaths: When? Where? Why? Lancet 2005;365(9462):891-900. doi: 10.1016/S0140-6736(05)71048-5. [PubMed: 15752534].

4. Sandall J, Devane D, Soltani H, Hatem M, Gates S. Improving quality and safety in maternity care: The contribution of midwife-led care. J Midwifery Womens Health. 2010;55(3):255-61. doi: 10.1016/j.jmwh.2010.02.002. [PubMed: 20434086].

5. Aboagye E, Agyemang OS. Maternal health-seeking behavior: The role of financing and organization of health services in Ghana. Glob J Health Sci. 2013;5(5):67-79. doi: 10.5539/gjhs.v5n5p67. [PubMed: 23985108]. [PubMed Central: PMC4776872].

6. Lawn JE, Blencowe H, Waiswa P, Amouzou A, Mathers C, Hogan D, et al. Stillbirths: rates, risk factors, and acceleration towards 2030. Lancet. 2016;387(10018):587-603. doi: 10.1016/S0140-6736(15)00837-5. [PubMed: 26794078].

7. Jolly SP, Rahman M, Afsana K, Yunus FM, Chowdhury AM. Evaluation of maternal health service indicators in urban slum of Bangladesh PLoS One. 2016;11(10). e0162825. doi: 10.1371/journal.pone.0162825. [PubMed: 27732596]. [PubMed Central: PMC5061363]. 
8. Warren C, Njuki R, Abuya T, Ndwiga C, Maingi G, Serwanga J, et al. Study protocol for promoting respectful maternity care initiative to assess, measure and design interventions to reduce disrespect and abuse during childbirth in Kenya. BMC Pregnancy Childbirth. 2013;13:21. doi: 10.1186/1471-2393-13-21. [PubMed: 23347548]. [PubMed Central: PMC3559298].

9. Chowdhury ME, Botlero R, Koblinsky M, Saha SK, Dieltiens G, Ronsmans C. Determinants of reduction in maternal mortality in Matlab, Bangladesh: A 30-year cohort study. Lancet. 2007;370(9595):13208. doi:10.1016/S0140-6736(07)61573-6. [PubMed: 17933646].

10. Paxton A, Bailey P, Lobis S, Fry D. Global patterns in availability of emergency obstetric care. Int J Gynaecol Obstet. 2006;93(3):300-7. doi: 10.1016/j.ijgo.2006.01.030. [PubMed: 16682039].

11. Luck M. Safe motherhood intervention studies in Africa: A review. East Afr Med J. 2000;77(11):599-607. doi: 10.4314/eamj.v77i11.46732. [PubMed: 12862106].

12. Vintzileos AM, Ananth CV, Smulian JC, Scorza WE, Knuppel RA. Prenatal care and black-white fetal death disparity in the United States. Obstet Gynecol. 2002;99(3):483-9. doi:10.1097/00006250-20020300000019.

13. Stephansson O, Dickman PW, Johansson AL, Cnattingius S. The influence of socioeconomic status on stillbirth risk in Sweden. Int J Epidemiol. 2001;30(6):1296-301. doi: 10.1093/ije/30.6.1296. [PubMed: 11821332].

14. Lowery C, Bronstein J, McGhee J, Ott R, Reece EA, Mays GP. ANGELS and University of Arkansas for Medical Sciences paradigm for distant obstetrical care delivery. Am J Obstet Gynecol. 2007;196(6):534 e1-9. doi 10.1016/j.ajog.2007.01.027. [PubMed:17547884].

15. Reece EA, Leguizamon G, Silva J, Whiteman V, Smith D. Intensive interventional maternity care reduces infant morbidity and hospital costs. J Matern Fetal Neonatal Med. 2002;11(3):204-10. doi: 10.1080/jmf.11.3.204.210. [PubMed: 12380679].

16. de Bernis L, Kinney MV, Stones W, Ten Hoope-Bender P, Vivio D, Leisher SH, et al. Stillbirths: Ending preventable deaths by 2030. Lancet. 2016;387(10019):703-16. doi:10.1016/S0140-6736(15)00954-X. [PubMed: 26794079].

17. Heazell AEP, Siassakos D, Blencowe H, Burden C, Bhutta ZA, Cacciatore J, et al. Stillbirths: Economic and psychosocial consequences. Lancet. 2016;387(10018):604-16. doi: 10.1016/S0140-6736(15)00836-3. [PubMed: 26794073].

18. The Irananian Ministry of Health and Medical Education (MOHME). The state of the world's children United Nations Children's Fund. 1999. Available from: http://behdasht.gov.ir/?siteid=1\&pageid=1508\& newsview $=184825$.

19. Tabrizi JS, Gholipoor K, Asghari Jafarabadi M, Farahbakhsh M, Mohammadzedeh M. Customer quality and maternity care in Tabriz urban health centers and health posts. J Clin Res Gov. 2012;1(1). doi: 10.13183/jcrg.v1i1.15.

20. Parsa P. Effect of prenatal health care on pregnancy outcomes in Hamadan, Iran. J Commun Med Health Educ. 2012;2(1). doi:10.4172/21610711.1000114

21. Ebrahimi Tavani M. Strengthening reproductive health and safe motherhood programs in Iran. 25thcongress medical women's International association. Tehran, Iran; 2001.

22. Aghlmand S, Akbari F, Lameei A, Mohammad K, Small R, Arab M. Developing evidence-based maternity care in Iran: A quality improvement study. BMC Pregnancy Childbirth. 2008;8:20. doi: 10.1186/1471-2393-8-20. [PubMed: 18554384]. [PubMed Central: PMC2443790].

23. Tabrizi JS, Askari S, Fardiazar Z, Koshavar H, Gholipour K. Service quality of delivered care from the perception of women with caesarean section and normal delivery. Health Promot Perspect. 2014;4(2):13743. doi: 10.5681/hpp.2014.018. [PubMed: 25650105]. [PubMed Central: PMC4300438].

24. Eden AR, Peterson LE. Impact of potential accreditation and certification in family medicine maternity care. Fam Med. 2017;49(1):14-21. [PubMed: 28166575].

25. Azarabadie S, Aghlmand S. The real quality of maternity care in Iran hospitals: A quality assessment study. IIOABJ Inst Integr Omics Appl Biotechnol J. 2016;7(sup2):611-7.

26. Medicine IO. Crossing the quality chasm: A new health system for the 21st century. Washington, DC: National Academy Press; 2001.

27. den Breejen EM, Nelen WL, Schol SF, Kremer JA, Hermens RP. Development of guideline-based indicators for patient-centredness in fertility care: what patients add. Hum Reprod. 2013;28(4):987-96. doi: 10.1093/humrep/det010. [PubMed: 23411619].

28. Biza A, Jille-Traas I, Colomar M, Belizan M, Requejo Harris J, Crahay $\mathrm{B}$, et al. Challenges and opportunities for implementing evidencebased antenatal care in Mozambique: A qualitative study. BMC Pregnancy Childbirth. 2015;15:200. doi: 10.1186/s12884-015-0625-x. [PubMed: 26330022]. [PubMed Central: PMC4557743].

29. Ganle JK, Otupiri E, Obeng B, Edusie AK, Ankomah A, Adanu R. Challenges women with disability face in accessing and using maternal healthcare services in Ghana: A qualitative study. PLoS One. 2016;11(6). e0158361. doi: 10.1371/journal.pone.0158361. [PubMed: 27347880]. [PubMed Central: PMC4922658].

30. Hoang H, Le Q, Ogden K. Women's maternity care needs and related service models in rural areas: A comprehensive systematic review of qualitative evidence. Women Birth. 2014;27(4):233-41. doi: 10.1016/j.wombi.2014.06.005. [PubMed: 25028188].

31. Graneheim UH, Lundman B. Qualitative content analysis in nursing research: concepts, procedures and measures to achieve trustworthiness. Nurse Educ Today. 2004;24(2):105-12. doi: 10.1016/j.nedt.2003.10.001. [PubMed: 14769454].

32. Vallely LM, Homiehombo P, Kelly AM, Vallely A, Homer CS, Whittaker A. Exploring women's perspectives of access to care during pregnancy and childbirth: A qualitative study from rural Papua New Guinea. Midwifery. 2013;29(10):1222-9. doi: 10.1016/j.midw.2013.03.011. [PubMed: 23684099].

33. Lacey A, Luff D. Qualitative data analysis nottingham: National institute for health research. orkshire and the Humber: The NIHR RDS for the East Midlands:; 2009.

34. Zamanzadeh V, Valizadeh L, Lotfi M, Salehi F. Burn Survivors' Experience of Core Outcomes during Return to Life: a Qualitative Study.J Caring Sci.2014;3(4):227-37. doi: 10.5681/jcs.2014.025. [PubMed: 25717453]. [PubMed Central: PMC4334175].

35. Kellaghan T, Stufflebeam DL. The international handbook of educational evaluation. Boston: Kluwer Academic Publishers; 2003. doi: 10.1007/978-94-010-0309-4.

36. Zhang G, Zeller N, Griffith R, Metcalf D, Williams J, Shea C, et al. Using the context, input, process, and product evaluation model (CIPP) as a comprehensive framework to guide the planning, implementation, and assessment of service-learning programs. J High Educ Outreach Engagem. 2011;15(4):57-84.

37. Ahmady S, Yazdi L. Exploring the midwifery training challenges in Iran from the viewpoint of faculty members and graduates of this field: Content analysis. J Med Educ. 2016;15(2):82-9.

38. Moghasemi S, Vedadhir A, Simbar M. Models for presentation of midwifery care and its challenges in Iran: A review study.J Holist Nurs Midwifery. 2018;28(1):64-74.

39. Makvandi S, Mirzaiinajmabadi K, Tehranian N. [The challenges of the physiologic childbirth program from the perspective of service providers: A qualitative approach]. J Hayat. 2018;24(3):244-60. Persian.

40. Joulaei H, Maharlouei N, Lankarani KB, Razzaghi A, Akbari M. Narrative review of women's health in Iran: Challenges and successes. Int J Equity Health. 2016;15:25. doi: 10.1186/s12939-016-0316-x. [PubMed: 26880036]. [PubMed Central: PMC4754925].

41. Mohammadi Y, Parsaeian M, Mehdipour P, Khosravi A, Larijani B, Sheidaei A, et al. Measuring Iran's success in achieving Millennium Development Goal 4: A systematic analysis of under-5 mortality at national and subnational levels from 1990 to 2015. Lancet Glob Health.2017;5(5):e537-44. doi:10.1016/S2214-109X(17)30105-5. [PubMed: 28363513]. 